\title{
The Past, Present, and Future of Special Collections Library Literature
}

\begin{abstract}
The field of bibliometrics provides a lens through which to explore how a journal's environment is shaped by the professionals that contribute to its creation and maintenance. Despite a rich legacy of bibliometric studies in Library and Information Science scholarship more generally, to date no studies have explored bibliometrics related specifically to special collections library literature. This study considers the Rare Books and Manuscripts Section (RBMS) of the Association of College and Research Libraries (ACRL) journals, RBML and RBM, to explore what it is possible to learn about late twentieth and early twenty-first century American special collections librarianship as a profession through an aggregate consideration of the professional literature. This study uses existing tools from author affiliation studies to explore the professional literature and available data about the perspectives that shaped the RBMS journals, RBML and RBM, to gain a better understanding of the particular ecosystem that informs research and publication in the field of American special collections librarianship.
\end{abstract}

\section{Introduction}

As Richard Saunders noted in a recent RBM editorial, journals and the professional literature they contain are vibrant, growing, and changing entities. ${ }^{1}$ Each issue is very much a product of the individuals who contributed content, the editorial board that helped develop that content, and the environment in which the contributions first appeared. The field of bibliometrics provides a lens through which to explore how a journal's environment is shaped by the professionals that contribute to its creation and maintenance.

This study considers the environment as found in the Rare Books and Manuscripts Section (RBMS) of the Association of College and Research Libraries (ACRL) journals, RBML (1986-1999) and RBM (2000-present). What can we learn about late twentieth and early twenty-first century American special collections librarianship as a profession through an aggregate consideration of our professional literature? What perspectives, both individual and institutional, are responsible

1. Richard Saunders, "Editor's Note (Read It This Time, Please)," RBM 19, no. 1 (Spring 2018): $11-12$.

๑) 2020 by Melanie Griffin (CC BY-NC [https://creativecommons.org/licenses/by-nc/4.0/]). 
for producing and therefore shaping our knowledge of special collections librarianship? First, this article will analyze trends among authors publishing in the journals, identifying the number of unique contributors, the number and types of institutions represented by the contributors, the ratio of single to group authorship, and the types of positions held by the contributors. Second, this article will analyze trends in publication patterns within both journals, identifying patterns in topics from frequently discussed themes as well as charting shifts in subject coverage within the journals over time. Finally, this article will consider the implications of these analyses. What perspectives, both individual and institutional, are responsible for producing and shaping our knowledge of special collections librarianship as it is found in RBMS journals? What lacunae exist in the current critical conversations around special collections librarianship? How might future research in the field address these gaps?

\section{Literature Review}

Although there are to date no studies exploring bibliometric data in special collections literature, bibliometric analysis has a rich history in library and information science (LIS) literature and allied fields. As the field is vast, the purpose of this review is not to provide a comprehensive overview or a history of the development of bibliometrics. Rather, it will instead chart the typical purposes of bibliometric analysis in LIS scholarship and determine the types of questions that these studies typically answer to provide a framework for the current study.

Citation analysis is a common tool in the field of bibliometrics, with an emphasis on quantifying the impact of a given article, author, or idea. Some of the many approaches to citation analysis in LIS include investigations of journal impact factors and how they work (or don't work), ${ }^{2}$ comparisons of different proprietary tools for conducting citation analyses, ${ }^{3}$ the use of altmetrics to articulate impact, ${ }^{4}$ and an exploration of the limitations of traditional citation analysis tools for social sciences and humanities publications. ${ }^{5}$ This list is by no means exhaustive, but it does suggest the varied array of approaches in LIS scholarship to studying the impact

2. Igor Fischer and Hans-Jakob Steiger, "Dynamics of Journal Impact Factors and Limits to Their Inflation,” Journal of Scholarly Publishing 50, no. 1 (October 2018): 26-36.

3. Kiduk Yang and Lokman I. Meho, "Citation Analysis: A Comparison of Google Scholar, Scopus, and Web of Science," Proceedings of the American Society for Information Science and Technology 43, no. 1 (2006): 1-15.

4. Jenny Wooldridge and Mike B. King, "Altmetric Scores: An Early Indicator of Research Impact," Journal of the Association for Information Science \& Technology 70, no. 3 (March 2019): 271-82.

5. See, for example, Éric Archambault et al., "Benchmarking Scientific Output in the Social Sciences and Humanities: The Limits of Existing Databases," Scientometrics 68, no. 3 (September 2006): 329-42; Kayvan Kousha and Mike Thelwall, "Google Book Search: Citation Analysis for Social Science and the Humanities," Journal of the American Society for Information Science and Technology 60, no. 8 (2009): 153749; Mike Thelwall, "Do Mendeley Reader Counts Indicate the Value of Arts and Humanities Research?" Journal of Librarianship \& Information Science 51, no. 3 (September 2019): 781-88. 
of an article after its initial publication and the networks through which scholarly literature travels.

Author affiliation studies are also prevalent within LIS bibliometric studies. These studies explore trends in authorship, including institutional and departmental affiliation of authors, ${ }^{6}$ disciplinary backgrounds of authors, ${ }^{7}$ faculty status of authors, ${ }^{8}$ and trends in authorship such as co-authorship and the number of articles individual authors typically produce. ${ }^{9}$ These methods have produced insights about the perspectives shaping knowledge production in library and information science, such as the proportional overrepresentation of LIS faculty as opposed to practicing librarians in the literature, ${ }^{10}$ as well as the introduction of new perspectives from computer science, business, and social sciences faculty joining the conversation over time. ${ }^{11}$ Other studies seek to quantify the effect of institutional perspectives involved in shaping the field, focusing on the institutional affiliation of authors at the time of publication and the proportional overrepresentation of a small number of four-year institutions in the literature. ${ }^{12}$

Also relevant to the present study are bibliometric analyses of the literature from allied fields, such as library history and digital humanities. One approach germane to this study stems from library history. It applies existing methods from bibliometric studies, including a quantitative analysis of authorship, institutional affiliation, professional status of authors, and topics covered, to the articles from specific journals in library history. ${ }^{13}$ Like special collections librarianship, library history has a small number of dedicated journals in which scholars tend to publish. For this reason, close examination of a small number of journals offers the ability for bibliometric analysis to provide "a snapshot of where we have been, who we are, and

6. Keith Swigger, "Institutional Affiliations of Authors of Research Articles," Journal of Education for Library and Information Science 26, no. 2 (Fall 1985): 105-09.

7. Carol A. Mularski, "Institutional Affiliations of Authors of Research Articles in Library and Information Science: Update," Journal of Education for Library and Information Science 31, no. 3 (Winter 1991): 179-86.

8. Quinn Bailbraith, et al., "Who Publishes in Top-Tier Library Science Journals? An Analysis by Faculty Status and Tenure," College \& Research Libraries 75, no. 5 (2014): 724-35.

9. Deborah D. Blecic, et al., "Publication Patterns of U.S. Academic Librarians and Libraries from 2003-2012," College \& Research Libraries 78, no. 4 (2017): 442-58; Ann C. Weller, Julie M. Hurd, and Stephen E. Wiberley Jr., "Publication Patterns of U.S. Academic Librarians from 1993 to 1997," College and Research Libraries 60, no. 4 (1999): 352-62; Stephen E. Wiberley Jr., Julie M. Hurd, and Ann C. Weller, "Publication Patterns of U.S. Academic Librarians from 1998 to 2002," College and Research Libraries 67, no. 3 (2006): 205-16.

10. Swigger, "Institutional Affiliation of Authors of Research Articles"; Mularski, "Institutional Affiliations of Authors of Research Articles in Library and Information Science: Update."

11. Mularski, "Institutional Affiliations of Authors of Research Articles in Library and Information Science: Update."

12. John M. Budd and Charles A. Seavey, "Characteristics of Journal Authorship by Academic Librarians," College \& Research Libraries 51, no. 5 (1990): 463-70.

13. Edward A. Goedeken, "What We Wrote about and Who We Were: Historical Writings in 'JLH' / 'L\&C,' 1966-2000," Libraries \& Culture 38, no. 3 (Summer 2003): 250-65. 
perhaps where we are going as historians of libraries and librarianship." ${ }^{14}$ Another approach to bibliometrics from library history focuses on quantifying "goodness" in library history research through an examination of self-citation patterns and citations to primary and secondary sources. ${ }^{15}$ Bibliometric analysis in digital humanities, meanwhile, focuses on casting a broader net and analyzing authorship to explore the unique contributions and advantages librarians can offer to the field of digital humanities, particularly when co-authorship between a librarian and a subject specialist occurs. ${ }^{16}$ The scholarship from these allied fields offers examples of bibliometrics within contained and sustained fields of inquiry and suggests fruitful avenues and questions for exploring authorship patterns in special collections librarianship, particularly in a small subset of journals.

No bibliometric studies of special collections scholarship currently exist, but the RBMS membership surveys ${ }^{17}$ and a subsequent analysis of the more recent 2015 membership survey ${ }^{18}$ provide a different lens through which to study the ecosystem of contemporary American special collections librarianship: RBMS membership demographics. As Healey and Nykanen note, these membership surveys represent an attempt to identify "who we [RBMS members] are as a community, how we have changed, and how we might continue to transform to meet the needs of our field." 19 Their analysis notes key ways that the field has remained static as well as ways that the profession evolved in a little more than 15 years. Both sets of survey results, for example, suggest a predominantly female field with a disproportionate number of men in senior management positions. ${ }^{20}$ In contrast to the 1997 survey respondents, however, the 2015 respondents skewed younger, ${ }^{21}$ were less likely to hold a doctoral degree, ${ }^{22}$ and had significant work experience in the rare book trade, teaching, or libraries outside a rare books setting in addition to special collections expertise. ${ }^{23}$ In the 2015 survey, participants provided a rallying cry for needed diversity within the field, both in terms of racial and ethnic diversity among

14. Goedeken, "What We Wrote about and Who We Were," 250.

15. Andrew B. Wertheimer, "Quantifying the 'Goodness' of Library History Research: A Bibliometric Study of the Journal of Library History / Libraries \& Culture," Libraries \& Culture 40, no. 3 (Summer 2005): 267-84.

16. Shun Han Rebekah Wong, "Digital Humanities: What Can Libraries Offer?" portal: Libraries and the Academy 16, no. 4 (October 2016): 669-90.

17. "1997 Membership Survey,” RBMS Membership \& Professional Development Committee, http://rbms.info/files/committees/membership_and_professional/rbms-survey97.pdf [accessed 10 October 2019]; "2015 RBMS Membership Survey: Data Report,” RBMS Membership \& Professional Development Committee, http://rbms.info/files/committees/membership_and_professional/2015_ RBMSDataReport.pdf [accessed 23 September 2019].

18. Elspeth Healey and Melissa Nykanen, "Channeling Janus: Past, Present, and Future in the RBMS Membership Survey," RBM 17, no. 1 (2016): 53-81.

19. Healey and Nykanen, "Channeling Janus," 54.

20. Healey and Nykanen, "Channeling Janus," 72.

21. Healey and Nykanen, "Channeling Janus," 58.

22. Healey and Nykanen, "Channeling Janus," 71.

23. Healey and Nykanen, "Channeling Janus," 61. 
practitioners as well as diversity in the types and sizes of institutions and collections represented in the association. ${ }^{24}$

This article fuses bibliometric analysis with the observations about the state of the special collections librarianship as a profession offered by the RBMS membership survey results. It uses existing tools from author affiliation studies to explore the professional literature and available data about the perspectives that shaped the literature as published in RBMS journals, $R M B L$ and $R B M$, to gain a better understanding of the particular ecosystem that informs research and publication in the field of American special collections librarianship.

\section{Journal Selection}

This study analyzes bibliometric trends in special collections library literature from 1986 to 2018. To do so, it relies on two RBMS journals solely dedicated to special collections librarianship: RBML (published 1986-1999) and its successor, $R B M$ (published 2000 to the present). Together, these two journals constitute the official journal of RBMS. It is important to note that these two journals do not encompass the entirety of special collections library literature. Most significantly, an open access journal devoted to special collections librarianship, The Reading Room: A Journal of Special Collections Librarianship, ran from 2016 to 2020. The short publication window, however, precludes the ability to make broader generalizations about this journal. Journals from the allied field of archival studies, such as American Archivist and Journal of Contemporary Archival Studies, often include literature on special collections librarianship. The study of archives, however, has its own distinct scholarly traditions, separate from the study of librarianship. ${ }^{25}$ This study focuses more narrowly on professional literature associated with the field of special collections librarianship rather than the field of archives and therefore does not include studies published in archives-specific journals. Similarly, topics related to special collections librarianship can appear in journals from the allied field of book history, such as $\mathrm{Pa}$ pers of the Bibliographical Society of America. As with archival studies, however, book history is a distinct field of study from special collections librarianship. Therefore, this study excludes scholarship published in book history journals.

Additionally, library science journals, particularly journals focusing on academic libraries, publish studies focusing on the practice of special collections librarianship. These articles, however, typically occur infrequently. Between 1939 and 2018, for example, College \& Research Libraries published only seven articles exclusively devoted to a facet of special collections librarianship. The Journal of Academic Librarianship

24. Healey and Nykanen, "Channeling Janus," 69.

25. William F. Birdsall, "Archivists, Librarians, and Issues during the Pioneering Era of the American Archival Movement," Journal of Library History 14, no. 4 (Fall 1979): 457-79. 
published 18 articles on special collections librarianship between 1993 and 2018, and portal: Journal of Libraries and the Academy published 16 special collections-focused articles in its 18 volumes that appeared between 2001 and $2018 .{ }^{26}$ There is not a general library and information science journal in which a critical mass of special collections librarianship articles appears, making it difficult to form generalizations about authorship trends in specific journals. Therefore, this article does not include articles published in general library and information science journals, although including articles from these journals represents a potential area for future research.

As the purpose, aim, and scope of a journal shapes the types of articles published in the journal, it is worth considering in brief the editorial aims of the journals that provide the data set for this analysis. In the inaugural editorial of $R B M L$, editor Ann Gwyn described the scope of the journal as "the theory and practices of special collections librarianship," including acquisitions, collection development, cataloging, conservation, security, development, exhibitions, and the use of technology in the provision of special collections library services. ${ }^{27}$ As editors Browar and Taylor noted in the final editorial for $R B M L$, over the course of publication the journal had charted shifts in the profession that led to a broadening of the field from the old, expensive, and rare to a plethora of formats, including the digitally mediated. ${ }^{28}$ Given the shifting nature of the profession, the editors argued that it was time for the journal and its name to shift as well, thereby emphasizing the "increased collaboration" in the field "with booksellers, collectors, museum professionals, conservators, and preservation specialists in all media, as well as scholars, students, archivists, fine printers, photographers, museum professionals, video producers, filmmakers, and anyone interested in and working to preserve cultural heritage." 29 Along with the change in name came a change in the journal's scope, shifting from an exclusive focus on librarianship to a more expansive conversation within the broader framework of cultural heritage stewardship.

\section{Methodology}

All peer-reviewed articles from $R B M L$ and $R B M$ through 2018 were analyzed for this study. Reviews, review essays, and editorials were not included in the data set. RBM in particular includes articles in many formats, and this study considers only pieces that the journal classifies as "research articles" or "articles." It excludes articles that

\footnotetext{
26. Searches for the keywords "special collections" conducted within each individual journal's search portal in January 2019. Results where "special collections" occurred only in a survey instrument or an article's footnotes were excluded from these tallies.

27. Ann Gwyn, "Editorial Statement," RBML 1, no. 1 (Spring 1986): 5.

28. Lisa Browar and Marvin J. Taylor, "Afterword: RBM: A Journal of Rare Books, Manuscripts, and Cultural Heritage," RBML 14, no. 1 (Fall 1999): 55-57.

29. Browar and Taylor, "Afterword: RBM: A Journal of Rare Books, Manuscripts, and Cultural Heritage," 56.
} 
the journal classifies as essays and RBMS business documents. RBML also published many RBMS business documents, although it did not consistently classify these pieces differently from research articles. To provide consistency in the data set between $R B M$ and $R B M L$, the author reviewed each article published in RBML and excluded RBMS business documents, such as the annual review of the Katharine Kyes Leab and Daniel J. Leab American Book Prices Current Exhibition Catalogue Awards.

For each article analyzed, the author harvested full citation information, including all named authors, title, author biographic statements, and article abstract. Information from these data points was extracted to create the following variables: author gender, institutional affiliation, job title, and functional specialty. Information from the data set was coded to create additional variables, including institution type (such as academic library, academic institution, public library, independent research library, museum, or book shop), Association of Research Libraries (ARL) member status, and Carnegie classification ${ }^{30}$ where relevant. Not all author biographic statements included all data points, so in the subsequent analysis the number of authorship statements under consideration fluctuates.

Coding for the variables "author gender" and "job title" required additional consideration. Gender was coded based on the personal pronouns used by the author in biographic statements. As all biographic statements included male or female pronouns, this study reports gender as a binary variable. There is substantial variation in job titles from institution to institution as reported in author biographic statements. Given the level of variation observed in the data set, the author took the following steps to normalize data around job titles to analyze the types of professionals contributing to the literature and their functional specialties. First, each job title as reported was assigned a normalized title, such as "Librarian," "Curator," "Archivist," or "Department Head." Normalized job titles were drawn from options provided in the 2015 RBMS Member Survey. ${ }^{31}$ After that normalization, each normalized job title was assigned a functional specialty extracted from the job title as reported, such as "Special Collections," "Cataloging," "Digital Collections," or "Administration-Special Collections." The same pattern was followed for nonlibrarian job titles. A reported job title of "Assistant Professor of English," for example, was coded with the normalized job title of "Professor" and a functional specialty of "English," while a rare books dealer was coded with the normalized job title of "Dealer" with a functional specialty of "book trade."

30. The Carnegie Commission on Higher Education developed and published a classification scheme for "describing institutional diversity in U.S. higher education." The original classification was published in 1973, and it was last updated in 2018. This study relies on data from the 2018 update. "About Carnegie Classification," The Carnegie Classification of Institutions of Higher Education, retrieved September 9, 2020, https:// carnegieclassifications.iu.edu/.

31. “2015 RBMS Membership Survey: Data Report." 
Finally, titles and abstracts provided a data set for coding thematic content in each article. In $R B M L$ and many issues of $R B M$, however, the abstract duplicates the first paragraph of the article and is not a true abstract. Therefore, abstracts are a less than ideal data source for content analysis in this study, and future research could provide additional granularity and specificity. For this reason, this study relies on both the title, which often includes relevant topical or thematic key words, and the abstract for thematic analysis. The author applied an inductive coding strategy to titles and abstracts, assigning at least two and up to three codes to each article analyzed. It is important to note that this study focuses exclusively on subjects covered in the journals, not how they cover those subjects. A case study on project management for digital collections, for example, probably covers very different questions, resources, and challenges in 2018 than a case study on the same topic that was published in 1998. Similarly, scholarly approaches to other fields of study, descriptive bibliography, also experience changes with time. The data set generated for this study, however, does not allow for analysis of changes in treatment of the subject over time, although these brief examples suggest that it could be a fruitful avenue for future research.

\section{Findings}

This study analyzes 282 articles in total; 104 were published in RBML between 1986 and 1999, and 178 were published in RBM between 2000 and 2018. These 282 articles contained 327 authorship attributions; 104 appeared in $R B M L$ and 217 in $R B M$. The articles were written by 306 uniquely named authors; 98 unique authors published in RBML and 208 in $R B M{ }^{32}$

\section{Trends in Authorship}

Almost all (326 of the 327 total) authorship attributions included gender-specific pronouns. A total of 173 (53.07 percent) of these authorship attributions used she/ her pronouns, while 153 (46.93 percent) used he/him pronouns. Of the 110 attributions occurring in RBML, 52 (47.27 percent) used she/her pronouns and 58 (52.73 percent) used he/him pronouns, while 121 (56.02) of the 216 attributions in $R B M$ used she/her pronouns and 95 (43.98 percent) used he/him pronouns. The remaining authorship attribution did not include pronouns. Over time, slightly more authors identifying as female have published in the journal, but the ratio remains skewed from the expected distribution, considering Healey and Nykanen's finding that special collections librarianship is a woman-dominated profession, with 77 percent of RBMS members in 2015 identifying as women. ${ }^{33}$

32. No effort was made to trace name changes.

33. Healey and Nykanen, "Channeling Janus," 79. 
The ratio of single-authored articles to collaborative articles published in the journals points to special collections librarianship's deep roots in the humanities. The singleauthor article is much more common in the humanities than it is in the social sciences or sciences. ${ }^{34}$ General LIS scholarship is situated in the middle of the spectrum, with approximately 50 percent of published articles being co-authored. ${ }^{35}$ Of the 282 articles published in RBML and RBM, however, 238 (84.4 percent) were single-author studies. Single authorship has decreased slightly over time, with 90 (86.54 percent) single-authored articles in the earlier RBML and 148 (83.14 percent) in RBM.

Existing LIS bibliometric scholarship has established the importance of repeat authorship in a journal or field of study, as well as the importance of institutional affiliation and disciplinary background of the represented authors. ${ }^{36}$ Special collections library literature as published in $R B M L$ and $R B M$ features the perspectives of many different individual authors, although the individual authors do share important characteristics, as discussed below. Of the 306 authors publishing in the journals, 285 (93.14 percent) published only one article (98 in RBML, 199 in RBM). Twenty-one authors published two articles; 12 authors published two articles in RBML, but only 9 have done so RBM. Although the research articles published in the journals were never dominated by a small group of individuals, in recent years even more individual perspectives have contributed to the discussion.

Although individual authors and institutional perspectives do not account for a majority of the research articles published in $R B M$ and $R B M L$, authors do share certain characteristics. A total of 322 authorship attributions included information about the position and institutional home of the author. Of these 322 individuals, 185 (57.45 percent) self-identified as academic librarians (67 of 107 in $R B M L$, or 62.62 percent in $R B M L$, and 188 of 215 authorship attributions in $R B M$ ). A further 42 authorship attributions indicated that the author is affiliated with a college or university, either as a professor or student (11 in RBML and 31 in $R B M$ ), bringing the total percentage of authors from academic institutions to 70.5 percent (see figure 1). In contrast to academic perspectives, other professional roles tend to be represented through the perspective of one or two authors; there is a long tail of professional positions held by very few authors in both $R B M L$ and $R B M$. A total of 56 coded job titles occurred across both RBML and RBM, and 44 of those titles occurred only once or twice and ranged from independent scholar to book artist, consultant, business partner, Peace Corps volunteer, editor, and law partner.

34. Björn Hellqvist, "Referencing in the Humanities and Its Implications for Citation Analysis," Journal of the American Society for Information Science and Technology 61, no. 2 (2010): 310-18.

35. Deborah D. Blecic et al., "Publication Patterns of U.S. Academic Librarians and Libraries from 2003-2012," 448.

36. John M. Budd and Charles A. Seavey, "Characteristics of Journal Authorship by Academic Librarians." 


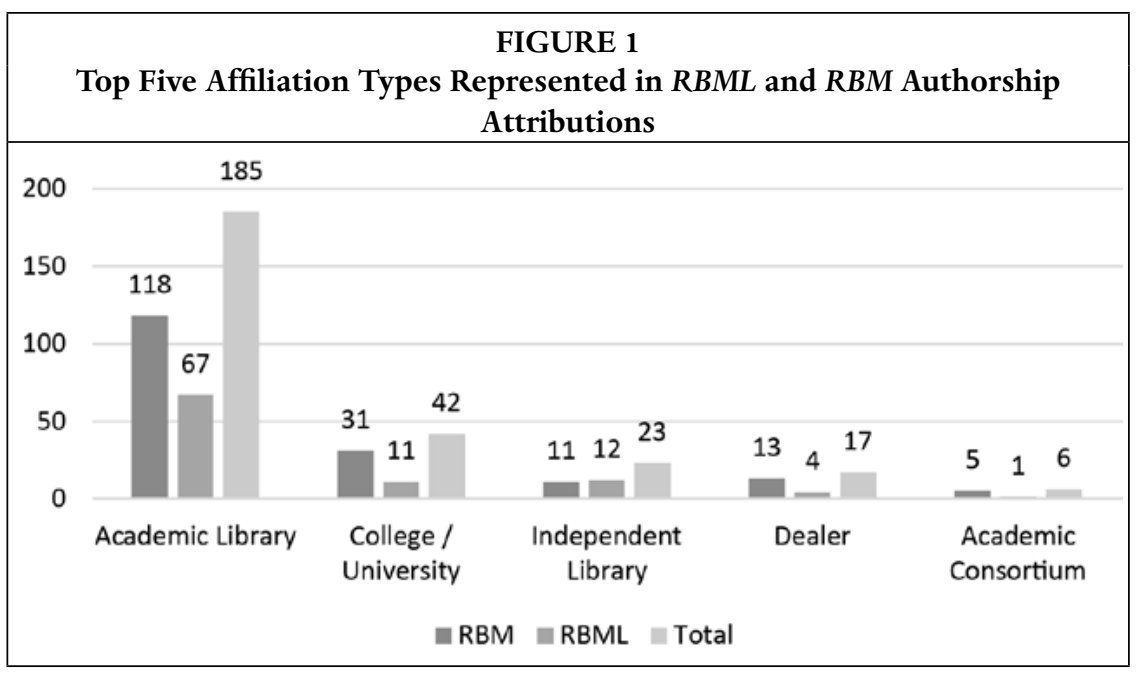

Special collections librarianship literature in these journals predominantly reflects the experiences of academic librarians and, to a lesser extent, academics from allied fields, typically in the humanities and arts. This is, perhaps, unsurprising given that the job requirements of many academic librarians and professors include research and publication for tenure or promotion. Additionally, as the official publication of the professional society RBMS, both $R B M L$ and $R B M$ have operated as a scholarly journal, offering neither authors nor reviewers remuneration for their work. Publication in these journals would therefore frequently represent professional work undertaken outside official working hours and job duties for professionals whose jobs do not require or, in some cases, allow for research and publication. As one of the editorial changes that occurred along with the journal's name was the desire to publish literature from a variety of perspectives throughout the cultural heritage sector, however, it remains a disappointing point of homogeneity. ${ }^{37}$ Instead, representation of academic perspectives in general and academic librarian perspectives in particular have increased.

Authorship attributions included 317 distinct institutional affiliations across $R B M L$ and $R B M$. Eleven authorship attributions indicated an institutional affiliation with the University of California at Los Angeles, 7 with New York University, 6 with Columbia University, 6 with the Harry Ransom Center at the University of Texas at Austin, and 5 with the University of Michigan (see figure 2). It is worth noting that all of the most frequently represented institutions hold memberships in ARL, ${ }^{38}$ and all are Carnegie-classified institutions of Doctoral Universities: Highest

37. Browar and Taylor, "Afterword: RBM: A Journal of Rare Books, Manuscripts, and Cultural Heritage."

38. At the time of writing, 124 libraries in the United States and Canada hold membership in ARL. 


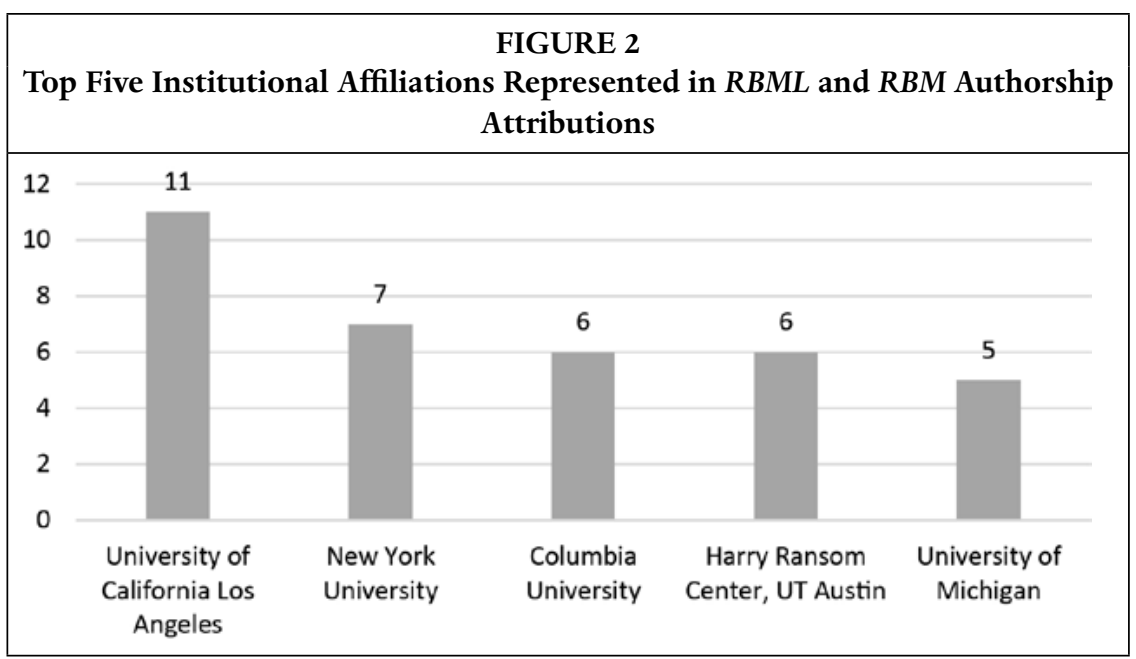

Research Activity. ${ }^{39}$ The most frequently represented institutions in RBML authorship attributions were the University of California at Los Angeles (7) and the University of Texas at Austin (4), with 9 institutions represented three times. In $R B M$, the most frequently represented institution is New York University (7), followed by the University of Michigan (5), and four institutions with four attributions. Notably, one of these is for Rostenberg \& Stern Rare Books - the only nonresearch library represented in these lists. Much like individual author representation in RBM and $R B M L$, there is a long tail of individual institutional representation among the journals' authors, with 133 institutions appearing only once in author affiliation statements, and a further 43 appearing twice.

Academic librarians and academics publishing in RBM and RBML share additional characteristics. Of the 318 authorship attributions that allowed for this type of analysis, 170 (53.46 percent) were by authors affiliated with an ARL member institution. Nearly half (102 of 211 , or $48.34 \%$ ) of the attributions in $R B M$ were from authors associated with ARL member libraries, as opposed to 68 of 107 (63.55\%) in $R B M L$ authorship attributions, indicating a slightly more diverse representation of academic library type in more recent years. Similarly, of the 208 authorship attributions indicating that the author was affiliated with a United States institution of higher education, 156 authors (75\%) were at an institution with a Carnegie classification of Doctoral Universities: Highest Research Activity, with 62 at a private university and 94 at a public university. A further 22 authors were affiliated with Doctoral Universities: Higher Research Activity (see table 1)..$^{40}$

39. In the 2018 Carnegie Classification, 115 out of the 4,105 institutions included received this classification. Carnegie Classification of Institutions of Higher Education, "2018 Update Facts \& Figures," retrieved September 9, 2020, https:/ / carnegieclassifications.iu.edu/downloads/CCIHE2018-FactsFigures.pdf.

40. Sixteen institutions were classified as Doctoral Universities with Higher Research Activity in 2018. 


\begin{tabular}{|l|c|c|c|}
\hline \multicolumn{4}{|c|}{ TABLE 1 } \\
Authorship Attributions \\
Carnegie Classification of Institutions Represented in RBML and RBM \\
\hline Classification & $R B M L$ & $R B M$ & Total \\
\hline Public Doctoral Universities: Highest Research Activity & 43 & 51 & 94 \\
\hline $\begin{array}{l}\text { Private, Not-for-Profit Doctoral Universities: Highest } \\
\text { Research Activity }\end{array}$ & 21 & 41 & 62 \\
\hline Public Doctoral Universities: Higher Research Activity & 4 & 10 & 14 \\
\hline $\begin{array}{l}\text { Private, Not-for-Profit Baccalaureate Colleges: Arts \& } \\
\text { Sciences Focus }\end{array}$ & 6 & 6 & 12 \\
\hline $\begin{array}{l}\text { Private, Not-for-Profit Doctoral Universities: Higher } \\
\text { Research Activity }\end{array}$ & 1 & 7 & 8 \\
\hline Public Doctoral Universities: Moderate Research Activity & 0 & 3 & 3 \\
\hline Public Master's Colleges \& Universities: Larger Programs & 1 & 2 & 3 \\
\hline $\begin{array}{l}\text { Private, Not-for-Profit Doctoral Universities: Moderate } \\
\text { Research Activity }\end{array}$ & 0 & 2 & 2 \\
\hline $\begin{array}{l}\text { Private, Not-for-Profit Master's Colleges \& Universities: } \\
\text { Larger Programs }\end{array}$ & 0 & 2 & 2 \\
\hline $\begin{array}{l}\text { Private, Not-for-Profit Master's Colleges \& Universities: } \\
\text { Medium Programs }\end{array}$ & 0 & 2 & 2 \\
\hline $\begin{array}{l}\text { Private, Not-for-Profit Master's Colleges \& Universities: } \\
\text { Medium Programs }\end{array}$ & 0 & 2 & 2 \\
\hline $\begin{array}{l}\text { Public Master's Colleges \& Universities: Medium } \\
\text { Programs }\end{array}$ & 1 & 1 & 2 \\
\hline $\begin{array}{l}\text { Private, Not-for-Profit Universities: Special Focus Four- } \\
\text { Year: Arts, Music, \& Design Schools }\end{array}$ & 0 & 1 & 1 \\
\hline $\begin{array}{l}\text { Private, Not-for-Profit Master's Colleges \& Universities: } \\
\text { Small Programs }\end{array}$ & 0 & 1 & 1 \\
\hline Public Master's Colleges \& Universities: Small Programs & 0 & 1 & 1 \\
\hline
\end{tabular}

A total of 319 authorship attributions included information about the author's position; 106 occurred in RBML and 213 in RBM. Within authorship attributions occurring in $R B M L$, the most commonly reported job title was department head (24), followed by librarian (16), curator (16), and professor (9). In $R B M$, librarian was the most commonly reported job title (38), followed by curator (23), director (20), professor (17), and department head (17). Despite these small fluctuations in commonly reported job titles across journals, administration is the most prevalent functional specialty. Within RBML attributions, 51 authors reported some type of administrative role, from special collections administration to general library and technical services administration. In RBM, administration remained the most common functional specialty, with 53 authors reporting an administra- 
tive role. Outside of administrator roles, librarian and curator were the most commonly reported job titles in both $R B M L$ and $R B M$. In $R B M L$, librarian and curator occurred at equal rates, with 16 authors identifying with each job title. In $R B M$, however, there was a slight shift, with 38 authors identifying as librarian and 23 as curator.

\section{Trends in Content}

This study relies on titles and abstracts to analyze general trends in the content of special collections library literature. The author used an inductive coding process to assign at least one and up to three codes to each article. Following this process, each article was assigned to one of four broad thematic categories based on the codes: administration and management, the state of the field, workflows and processes, and stewardship.

The thematic category of "administration and management" includes literature that focuses on management practices across the profession, including project management as well as more traditional administrative roles focused on personnel and fiscal management. Unsurprisingly, given the large percentage of $R B M L$ and $R B M$ authors who work in some type of administration or management, this thematic category is quite large. It covers the entire spectrum of special collections librarianship: project management for cataloging, processing, deaccessioning, preservation and conservation, digital collections, and collection development; budgets and personnel management; cross-unit collaborations; cross-institution collaborations; and change management.

The thematic category of "workflows and processes" includes articles that explore best practices for special collections librarianship. Secondary codes applied to these articles indicate the range of topics considered: methods for reducing cataloging and processing backlogs, special format cataloging, interlibrary lending, exhibitions, disaster planning, security, applying for and implementing grants, crafting access policies, conducting outreach, and working with development to raise funds that support the mission of special collections libraries.

A number of tags, including "the education of special collections librarians," "recruitment practices," "the future of special collections librarianship," "continuing education," "professional standards," and "professional relationships" (both interand intra-institutional), were clustered together under the thematic heading of "the state of the field." Taken together, these articles suggest a concern in the literature with what special collections librarianship is, how future members of the profession receive training, and what the field will look like in the future. 
Finally, the articles clustered under the category of "stewardship" focus on the curation, care, and user needs related to materials in special collections libraries. The materials considered in these articles span a wide range of specific subjects and formats, and the articles include methods for making collections accessible and connecting communities to collections.

The individual codes assigned to articles are also illuminating, particularly in the ways that they span the two journals or appear in isolation in either RBML or the later RBM. The codes "bibliography" and "collections," for example, were applied to articles in both journals at similar rates, suggesting a continued interest in the study of the history of the book and the materials under special collections librarians' care. Secondary codes applied to articles with the primary codes of "bibliography" or "collections" illustrate the wide range of materials with which special collections librarians work: ephemera, artists' books, incunables, Medieval manuscripts, nineteenth-century published works, modern records, literary collections, artifacts and publications documenting the history of medicine, the illustrated book, the rare book trade, strategies for working with foreign language materials, maps, children's books, and visual materials, to name just a few. The abstracts associated with articles that received these codes, however, suggest a bias in both journals toward bibliographic study of collections materials from Europe and North America. No articles received codes that suggest the presence of significant analysis of bibliographic study of materials related to indigenous peoples or racial or ethnic minorities. Only one article was coded as including an analysis of LGBTQ+ collections. These topical elements may be covered in the journals, but they were not noted in article titles or abstracts.

Similarly, security and procedures for interlibrary lending of special collections materials appear frequently in both journals, indicating longstanding and continued conversations around these topics that are unsurprising given the increased risks associated with caring for materials in special collections repositories. Another perennially popular topic in both journals is the future of special collections librarianship. Frequently, these codes occur concurrently with "education of future librarians," suggesting that this body of literature is concerned not only with where the profession is going but how we might get there.

Other codes illustrate shifts in the profession and professional concerns. Unsurprisingly, given the dates associated with each journal's publication, only one article received the code "digital" in RBML; "digital collections" is, in contrast, a frequently applied code to articles in RBM. Similarly, articles on social media appear only in $R B M$. Although "outreach" is a commonly applied code in both journals, "teaching with special collections" and "instruction" appear only in $R B M$, potentially sug- 
gesting a paradigm shift in outreach activities associated with special collections librarianship. Other codes that only apply to RBM articles include "access" and "assessment," pointing to additional ways that professional concerns have shifted in recent years.

\section{The Future of Special Collections Library Literature}

This study highlights areas for further research, both about special collections library literature and within the field of special collections librarianship. Further study is needed to assess the state of special collections library literature outside of RBMS journals. Do the trends noted in RMBL and RBM occur in other publications? How do trends in North American special collections library literature compare to trends in other countries? Abstracts in both journals are consistently poor indicators of content and do not allow for analysis of shifting approaches to the similar topics or methodologies, so further content analysis using a larger text base is warranted.

This study illuminates some homogenous areas within the sample studied and suggests the need for additional voices and perspectives in the study of special collections librarianship. A significant number of studies share the perspectives of librarians, frequently administrators or managers, associated with academic libraries. Further, these libraries are typically located at research-intensive and/or ARL member institutions. Outside of academic librarians, the most frequent contributors to the journals are academics associated with research-intensive universities and professionals from the rare book trade. The long tail of articles authored by individuals with different professional roles indicates the diverse nature of perspectives available to special collections library literature; normalizing academic perspectives leads to a reductive view of the field and professional practice.

Neither RBML nor RBM provides significant insight into special collections librarianship as practiced at smaller academic institutions, historically black colleges and universities, tribal colleges, public or government libraries outside of ARL institutions, state libraries, historical societies, independent research libraries, or private libraries. Although the shift in publication focus in RBM has introduced a greater variety of individual perspectives, these perspectives are typically limited to the voice of one practitioner or one librarian from a college or university that is not research intensive. The critical mass of literature does not exist for these perspectives as it does for academic librarians at research-intensive universities. To gain a more nuanced, complete picture of the practice of special collections librarianship, we need literature that shares the perspectives of professionals working in different environments, with different constituencies, and with different collections. 


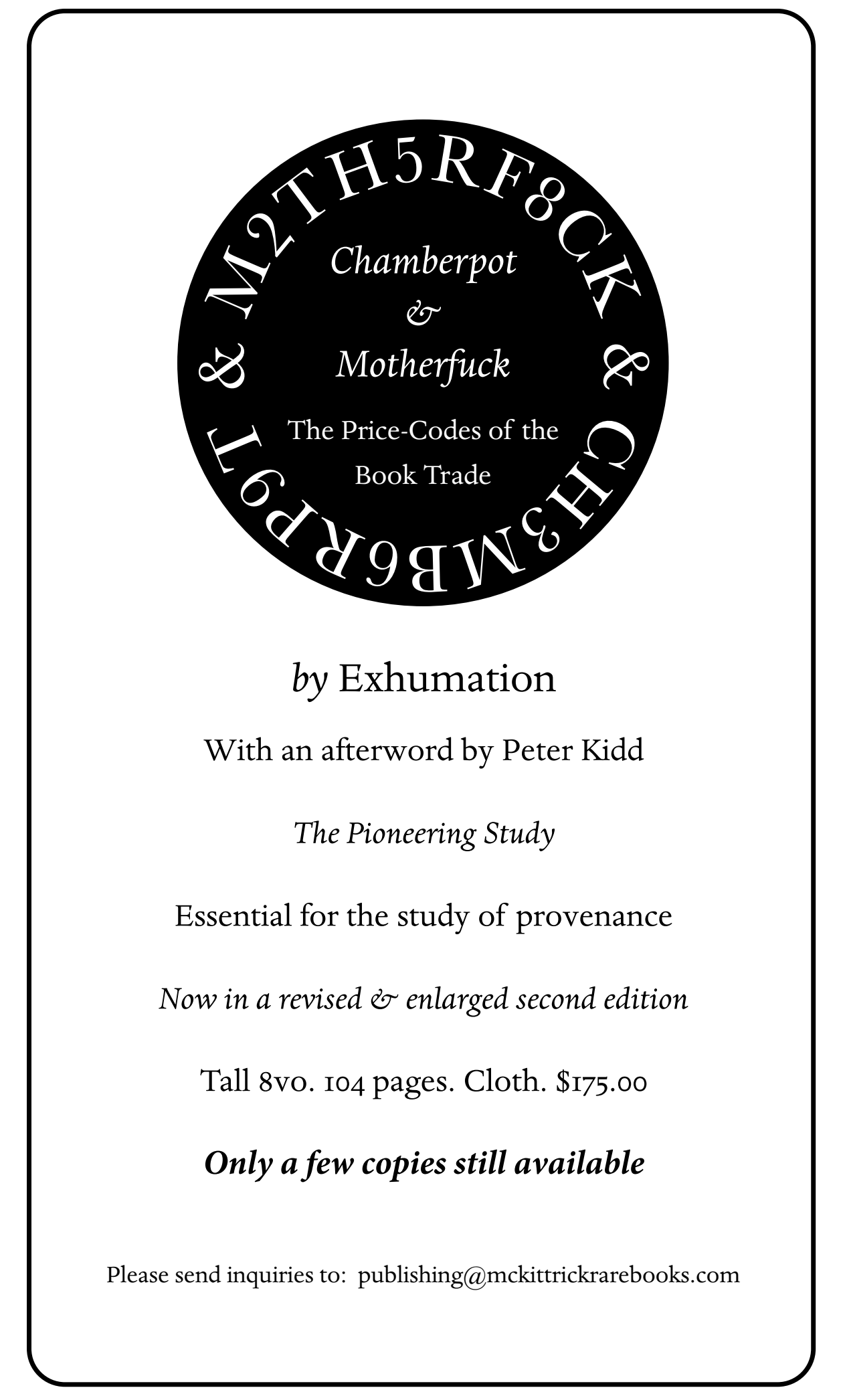

